\title{
Clinical Features and Gene Mutation Analysis of Congenital Thrombotic Thrombocytopenic Purpura in Neonates
}

OPEN ACCESS

Edited by:

Offer Erez,

Soroka Medical Center, Israel

Reviewed by:

Aakash Pandita

Sanjay Gandhi Post Graduate Institute of Medical Sciences (SGPGI), India

Oleg Pikovsky,

Soroka Medical Center, Israel

*Correspondence:

Li Zhao

zhaoli_dr@163.com

Specialty section:

This article was submitted to Neonatology,

a section of the journal

Frontiers in Pediatrics

Received: 27 March 2020

Accepted: 17 August 2020

Published: 22 September 2020

Citation:

Wang J and Zhao L (2020) Clinical Features and Gene Mutation Analysis of Congenital Thrombotic

Thrombocytopenic Purpura in

Neonates. Front. Pediatr. 8:546248.

doi: 10.3389/fped.2020.546248

\author{
Jiali Wang and Li Zhao* \\ Department of Neonatology, Children's Hospital of Nanjing Medical University, Nanjing, China
}

Congenital thrombotic thrombocytopenic purpura (TTP) is a rare hereditary disease with a high mortality rate; however, improved patient survival is possible with prompt diagnosis and treatment. The clinical features and mutation sites of a disintegrin and metalloproteinase with thrombospondin motifs 13 (ADAMTS13) in congenital TTP were analyzed in a neonate with suspected congenital TTP. High-throughput sequencing, polymerase chain reaction, and Sanger sequencing were utilized for screening of genes related to thrombocytopenic diseases and ADAMTS13 gene mutation testing on blood samples from the neonate and the parents. Domestic and foreign literature reporting the clinical features and variants of ADAMTS13 in neonates with congenital TTP were retrieved, compared, and analyzed. The patient in this case was a girl who had been born for $1 \mathrm{~h}$ and admitted to the hospital due to "dyspnea for $1 \mathrm{~h}$." Routine blood tests on admission revealed profound thrombocytopenia. She quickly developed symptoms of systemic hemorrhage and eventually died. The neonate had two older sisters who had died of idiopathic thrombocytopenia and hemorrhage within $24 \mathrm{~h}$ of birth. Genetic testing showed that the neonate harbored a compound heterozygous mutation in ADAMTS13, c. $1187 \mathrm{G}>\mathrm{A} / \mathrm{c} .1595 \mathrm{G}>\mathrm{T}$, which is a novel variant. Of the 12 cases (1 case in China and 11 cases in other countries) of congenital TTP in neonates that have been reported globally, ADAMTS13 mutation analysis was only performed in eight neonates. Common clinical manifestations included dyspnea of unknown etiology, bruising, jaundice, hemorrhage, and thrombocytopenia. Hence, the current case contributes to our understanding of the clinical manifestations and types of variants in neonates with congenital TTP. Our results demonstrate the efficacy of high-throughput sequencing technology in genetic testing of neonates suspected with congenital TTP and have revealed a novel compound missense mutation in ADAMTS13 that has not been reported in China or elsewhere.

Keywords: congenital thrombotic thrombocytopenic purpura, ADAMTS 13, gene mutation, neonates, congenital disease, genetic testing, family history

\section{INTRODUCTION}

Congenital thrombotic thrombocytopenic purpura (TTP) is a rare hereditary disease characterized by periodic episodes of microangiopathy, hemolytic anemia, thrombocytopenia, and organ damage of variable severity. These symptoms may occur during the neonatal period, but their first appearance may also occur after adulthood. If not treated promptly, onset of congenital TTP 
has a high mortality rate. However, most patients can survive if timely diagnosis and treatment are provided (1). The relevant TTP registry showed that the annual incidence of congenital TTP is (1-3)/1,000,000 (2); however, the pathogenesis of TTP remains unclear. Currently, the prevailing opinion is that the cause of TTP is multifactorial, including extensive injury of the vascular endothelium, reduced prostacyclin concentration in blood, and the formation of von Willebrand factor (VWF) multimers due to impaired cleavage of ultra-large von Willebrand factor (ULVWF), in addition to the damaging effects of autoantibodies and oxidants that promote platelet activation. In recent years, the discovery of UL-VWF multimers, purification of VWFcleaving protease (VWF-CP), and cloning of ADAMTS13 have led to the belief that a deficiency of the ADAMTS13 enzyme is the major mechanism underpinning TTP pathogenesis (3). Additionally, thrombin-sensitive protein 1 (TSP1), abnormal complement regulation, anti-endothelial cell antibody (AE$\mathrm{CA}$ ), and excessive release of VWF multimers have been associated with the onset of TTP (4). Under physiological conditions, the ADAMTS13 enzyme in the plasma specifically cleaves VWF multimers into small molecular fragments, thereby regulating normal coagulation function. When ADAMTS13 enzymes are deficient, such as due to the presence of ADAMTS13 mutations or autoantibodies against the ADAMTS13 enzyme, the VWF multimers cannot be cleaved normally. This leads to a large amount of UL-VWF in blood circulation, resulting in extensive microvascular thrombosis and damage to multiple organs, thereby triggering the onset of TTP. A significant reduction in ADAMTS13 enzyme activity and the negativity of antibody against ADAMTS13 enzyme detected through laboratory testing are the key indicators of TTP diagnosis. Meanwhile, the combination of high-throughput sequencing, polymerase chain reaction (PCR), and Sanger sequencing can be used for prenatal screening and diagnosis in individuals with a family history of TTP. In this study, genetic screening was performed in a neonate with a suspected diagnosis of congenital TTP. Pedigree verification was conducted for the mutant gene identified, and the congenital TTP diagnosis was confirmed. Finally, the clinical features and genetic variants of congenital TTP in neonates from domestic and foreign reports were analyzed.

\section{MATERIALS AND METHODS}

\section{General Information}

Our patient's father signed a written consent for publication of her clinical information and her pictures according to Children's Hospital of Nanjing Medical University's internal policies and statutes. The patient was a girl who had been born for $1 \mathrm{~h}$. She was the third child carried and delivered by the mother. Her gestational age was $39^{+3}$ weeks. The mother had chronic hypertension with pre-eclampsia, and the patient was delivered vaginally. Her birth weight was 3,600 g, and her Apgar scores at 1 and 5 min were 8 and 9 , respectively. The mother had been pregnant and had live-born baby girls twice before; however, both girls had died of jaundice and hemorrhage within $24 \mathrm{~h}$ of birth. The neonatal patient in the present case was admitted to the hospital due to dyspnea. Hemorrhage sites appeared throughout the body immediately after admission, and the number of sites gradually increased. Mechanical ventilation was provided to alleviate uncontrolled hemorrhage at puncture sites and symptoms of pulmonary hemorrhage. Prothrombin complex was administered for hemostasis, and platelet transfusion was performed. However, the symptoms of the patient did not improve. The parents gave up treatment $6 \mathrm{~h}$ after admission and the patient died. The first child was born and died in the obstetrics and gynecology department of a different hospital; however, details of laboratory test results and treatments provided were not available. The second child was admitted to our hospital after birth with jaundice. Upon admission, the patient exhibited symptoms such as oliguria, edema, systemic hemorrhage, uncontrolled hemorrhage at puncture sites, and progressive thrombocytopenia. Anti-infection and hemostatic treatments were given. The neonatal patient died $9 \mathrm{~h}$ after admission. The laboratory test results for the second and third births are shown in Table 1. None of the three neonatal patients were tested for ADAMTSI3 enzyme activity and antibodies.

\section{Screening for Inherited Metabolic Diseases}

Peripheral blood $(\sim 2 \mathrm{ml})$ was drawn from the neonatal patient $5 \mathrm{~h}$ after admission and placed in a tube containing ethylenediaminetetraacetic acid (EDTA) as an anticoagulant. The sample was sent to the Beijing Full Spectrum Medical Laboratory for testing. Whole exome sequencing was performed using the xGen Exome Research Panel v1.0 from Integrated DNA Technologies (IDT) and sequencing was completed using the Illumina NovaSeq 6000 series sequencing system. The coverage of the target sequences was maintained $>99 \%$. Screening was conducted in a cloud-based platform, for precision diagnosis of thrombocytopenic diseases that integrated molecular biology annotations and analyses of biology, genetics, and clinical features. In addition, the pathogenic variant database, normal human genome database, and database containing the clinical features of 4,000 known genetic diseases were queried. Using the algorithms for genetic data analysis, several hundred thousands of genetic variants were classified. Variant classification was performed using the 3-tier classification system and the American College of Medical Genetics and Genomics (ACMG) variant classification system. PCR amplification of the target sequences was performed, and the sequences were validated through Sanger sequencing using the ABI3730 sequencer. Validation results were obtained using a sequence analysis software. Genetic testing results are shown in Table 2.

\section{Literature Search}

The keywords for literature search were "thrombotic thrombocytopenic purpura" and "Upshaw-Schulman syndrome." Literature were retrieved from China National Knowledge Infrastructure, Wanfang Data, and PubMed using neonatal patients of $\leq 28$-day-old as a criterion to obtain data and case reports of neonates with congenital TTP. 
TABLE 1 | Laboratory test results for two of the live-born children of the neonatal patient's mother.

\begin{tabular}{|c|c|c|c|c|c|c|c|c|c|}
\hline & \multicolumn{2}{|c|}{$\begin{array}{c}\text { Hemoglobin }(g / L) \\
(140-180)\end{array}$} & \multicolumn{2}{|c|}{$\begin{array}{l}\text { Platelets }\left(\times 10^{9} / \mathrm{L}\right) \\
(100-300)\end{array}$} & \multicolumn{2}{|c|}{$\begin{array}{l}\text { MCV (fL) } \\
(80-100)\end{array}$} & $\begin{array}{c}\text { Lactate } \\
\text { dehydrogenase } \\
\text { (U/L) (185-407) }\end{array}$ & $\begin{array}{c}\text { Bilirubin } \\
\text { ( } \mu \mathrm{mol} / \mathrm{L}) \\
(3.4-17.1)\end{array}$ & $\begin{array}{c}\text { International } \\
\text { Normalized Ratio } \\
\text { (INR) (0.82-1.15) }\end{array}$ \\
\hline 2nd birth & 65 & 30 & 146 & 28 & 97.7 & 104.2 & 2,897 & 433.78 & 2.38 \\
\hline
\end{tabular}

TABLE 2 | Data on genetic variants.

\begin{tabular}{|c|c|c|c|c|c|c|c|c|c|c|c|}
\hline Gene & $\begin{array}{c}\text { Serial } \\
\text { number }\end{array}$ & $\begin{array}{l}\text { Chromosome } \\
\text { r location }\end{array}$ & $\begin{array}{l}\text { Nucleic acid } \\
\text { changes }\end{array}$ & $\begin{array}{l}\text { Amino acid } \\
\text { changes }\end{array}$ & $\begin{array}{l}\text { RS } \\
\text { number }\end{array}$ & MAF & $\begin{array}{l}\text { ACMG } \\
\text { pathogenic } \\
\text { variant class }\end{array}$ & Proband & Father & Mother & $\begin{array}{l}\text { OMIM number of } \\
\text { related diseases, } \\
\text { mode of inheritance }\end{array}$ \\
\hline ADAMTS13 & 1 & $\begin{array}{l}\text { chr9:13 } \\
6303376\end{array}$ & $\begin{array}{l}\text { c.1595(exon } \\
\text { 14) } G>T\end{array}$ & $\begin{array}{l}\text { p.C532F } \\
\text { (p.Cys532Phe) }\end{array}$ & None & $\begin{array}{l}\text { Not } \\
\text { recorded }\end{array}$ & Uncertain & $\begin{array}{l}\text { Heterozygous } \\
29 / 55\end{array}$ & Wild type 0/54 & Hybrid 30/61 & $\begin{array}{l}\text { TTP (OMIM: 274150), } \\
\text { AR }\end{array}$ \\
\hline & 2 & $\begin{array}{l}\text { chr9:13 } \\
6298592\end{array}$ & $\begin{array}{l}\text { c. } 1187 \text { (exon } \\
\text { 10) } \mathrm{G}>\mathrm{A}\end{array}$ & $\begin{array}{l}\text { p.C396Y } \\
\text { (p.Cys396Tyr) }\end{array}$ & None & $\begin{array}{l}\text { Not } \\
\text { recorded }\end{array}$ & Uncertain & $\begin{array}{l}\text { Heterozygous } \\
30 / 54\end{array}$ & $\begin{array}{l}\text { Heterozygous } \\
49 / 102\end{array}$ & Wild type 0/46 & \\
\hline
\end{tabular}

TABLE 3 | Clinical features and prognoses of 12 neonates with congenital TTP.

\begin{tabular}{|c|c|c|c|c|c|c|c|c|c|c|c|c|c|}
\hline $\begin{array}{l}\text { Case } \\
\text { number }\end{array}$ & Sex & Time of onset & Jaundice & Hematuria & Anemia & Thrombocytopenia & Fever & Seizure & $\begin{array}{l}\text { Abnormal renal } \\
\text { function }\end{array}$ & $\begin{array}{l}\text { ADAMTS13 } \\
\text { activity }\end{array}$ & $\begin{array}{l}\text { Family } \\
\text { history }\end{array}$ & Outcome & References \\
\hline Case 1 & Girl & $40 \mathrm{~h}$ after birth & + & + & + & + & + & - & + & $<1 \%$ & + & Deceased & (5) \\
\hline Case 2 & Boy & 1 day after birth & + & + & + & + & - & - & - & $5 \%$ & - & Survived & (6) \\
\hline Case 3 & Boy & 3 days after birth & + & - & + & + & + & - & - & $4 \%$ & + & Survived & (6) \\
\hline Case 4 & Girl & $6 \mathrm{~h}$ after birth & + & + & + & + & - & + & - & $10 \%$ & - & Survived & (7) \\
\hline Case 5 & Boy & $11 \mathrm{~h}$ after birth & + & - & + & + & - & - & - & $<0.5$ & - & Survived & (8) \\
\hline Case 6 & Girl & 1 day after birth & + & - & - & + & - & - & + & $0.5 \%$ & - & Survived & (8) \\
\hline Case 7 & Boy & $4 \mathrm{~h}$ after birth & + & + & + & + & - & - & + & $5 \%$ & - & Survived & (9) \\
\hline Case 8 & Boy & $6 \mathrm{~h}$ after birth & + & - & + & + & - & - & + & $<5 \%$ & - & Survived & $(10)$ \\
\hline Case 9 & Girl & $4 \mathrm{~h}$ after birth & + & + & + & + & - & - & + & $10 \%$ & + & Survived & (11) \\
\hline Case 10 & Girl & 1 day after birth & + & - & + & + & - & - & - & $0.5 \%$ & - & Survived & $(12)$ \\
\hline Case 11 & Boy & Not specified & + & - & + & + & - & - & - & - & - & Deceased & (13) \\
\hline Case 12 & Boy & 27 days after birth & + & - & + & + & - & + & + & $<10 \&$ & - & Deceased & (14) \\
\hline
\end{tabular}

\section{RESULTS}

\section{Analysis of Clinical Features}

Literature search revealed 12 cases of congenital TTP in neonates reported worldwide. The clinical features and prognoses of the cases are described in Table 3.

\section{DNA Sequencing Results}

Trio whole exome sequencing was performed in the Illumina NovaSeq 6000 series sequencing system. The exonic regions of about 20,000 genes in the human genome were sequenced. The coverage of the target sequences was no $<99 \%$. In the sample of the present case, ADAMTS13 exhibited a c.1187G $>$ A (p.C396Y) missense mutation in exon 10 and a c.1595G $>$ T (p.C532F) missense mutation in exon 14. A search in the Human Gene Mutation Database (HGMD) did not reveal any published report on these 2 variants, suggesting that the mutations in these two locations are novel variants of ADAMTS13. Pedigree verification using PCR amplification and Sanger sequencing showed that the father of the neonatal patient harbored the c.1187G >A (p.C396Y) mutation, and the mother harbored the c.1595G $>$ T (p.C532F) mutation (Figure 1). Hence, the patient's family met the criteria for the pathogenesis of autosomal recessive (AR) inheritance.

\section{ADAMTS13 Mutation Analysis}

Among the 12 cases reported thus far (5-14), gene mutation analysis was performed in eight cases (Table 4), one of which the mutation was not specified. The neonatal patient in case 1 only harbored one mutation, whereas the patients in the remaining six cases all harbored a compound heterozygous mutation; missense mutations and deletions in cases 3 and 5, and an insertion in case 7. The older brother of the patient in case 3 harbored the same gene mutation, but neonatal onset of the disease did not occur. The parents and two older brothers of the patient in case 5 were heterozygous carriers harboring one of the two mutations. In case 6 , each parent harbored a mutant gene. Family members of the 

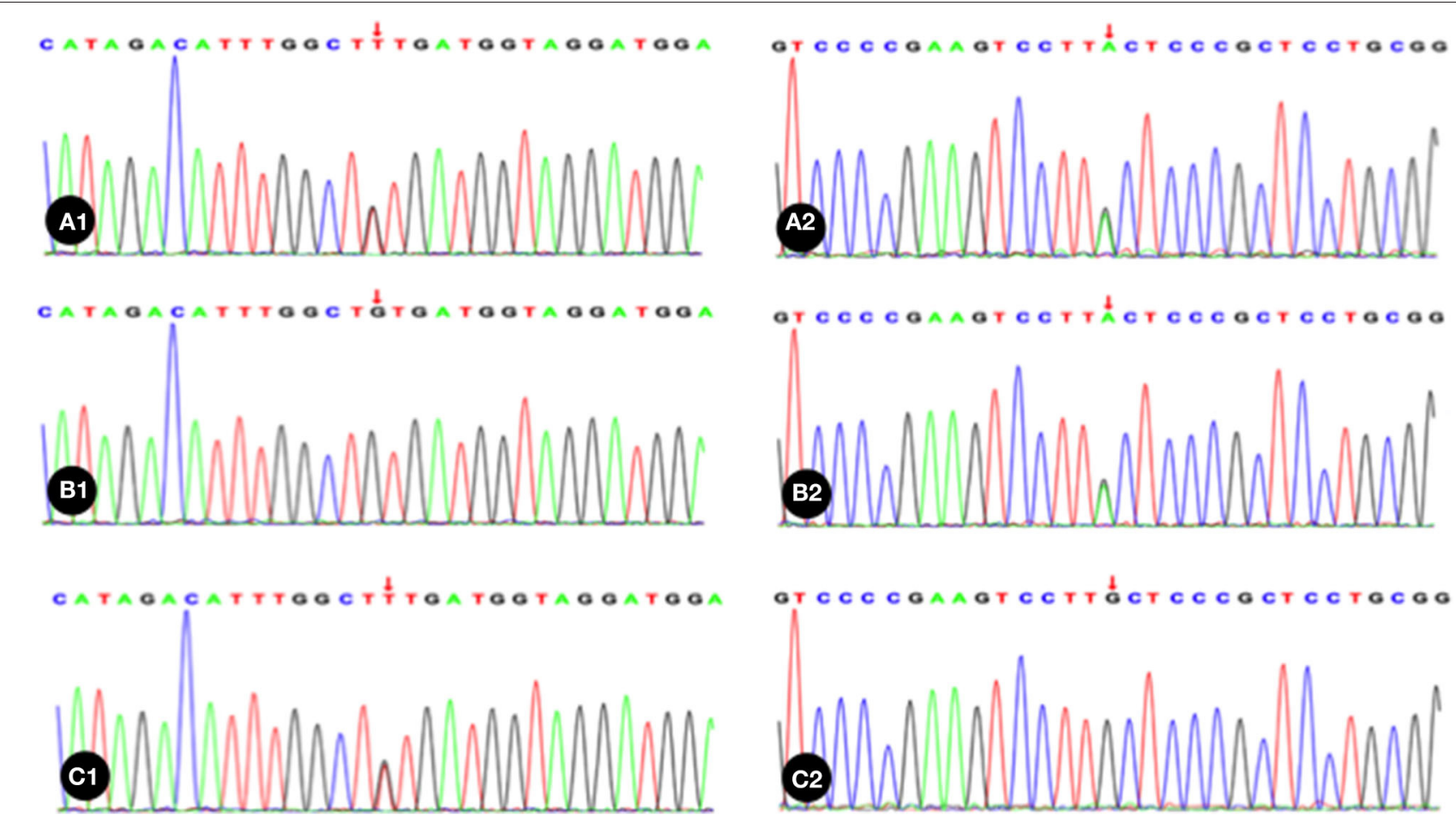

FIGURE 1 | The neonatal patient harbored a mutation of C.1595G>T in 1 allele; B1, Absence of mutation in the patient's father; C1, The patient's mother harbored a heterozygous mutation of C.1187G >A; A2, The neonatal patient harbored a mutation of c.1187G>A in 1 allele; B2, The patient's father harbored a heterozygous mutation of $\mathrm{c} .1187 \mathrm{G}>\mathrm{A} ; \mathrm{C} 2$, Absence of mutation in the patient's mother. Red arrow indicates the nucleotide position of the mutation.

TABLE 4 | Mutation analysis of the ADAMTS13 in neonatal patients with congenital TTP.

\begin{tabular}{|c|c|c|}
\hline Case number & Genetic variant & References \\
\hline Case 1 & c.2203(exon18)G>T & (5) \\
\hline Case 2 & c.2104(exon17)G >C; c.2281(exon19)G>A & (6) \\
\hline Case 3 & delEx15+16; c.3655C>T & (6) \\
\hline Case 4 & c.415-10G >A; c.824+13C>T; c.2017A >T & (7) \\
\hline Case 5 & c.1192(exon10) C>T; c.2167(exon18) C>A & (8) \\
\hline Case 6 & c.1345(exon 12)C>T; c.4119(exon 29)del & (8) \\
\hline Case 7 & c.3100(exon 24)A>T; c.4143(exon 29)ins A & $(12)$ \\
\hline
\end{tabular}

neonatal patients in the remaining three cases did not undergo genetic testing.

\section{DISCUSSION}

The typical clinical manifestations of congenital TTP include five signs and symptoms: fever, microangiopathic hemolytic anemia, thrombocytopenia, renal dysfunction, and neurological symptoms. The neonate with congenital TTP in the present case and those in literature reports all exhibited severe signs of thrombocytopenia, jaundice and hemorrhage; however, none of the patients exhibited all five signs and symptoms, suggesting that congenital TTP lacked specific clinical features in neonates, and could be easily misdiagnosed as other conditions, such as immune thrombocytopenic purpura (ITP), Evans syndrome, hemolytic-uremic syndrome, or severe infection. Determination of ADAMTSI3 enzyme activity was conducted in 11 neonatal patients reported in the literature after the onset of disease, and the enzyme activity was $<10 \%$ in all cases. Nine neonatal patients were treated with plasma exchange. They received regular fresh frozen plasma transfusions and achieved long-term survival. Of the 11 cases, only 2 deaths occurred. In one case, ADAMTS13 enzyme activity was not determined. The patient died $34 \mathrm{~h}$ after birth, and postmortem genetic testing confirmed a diagnosis of congenital TTP. For the neonatal patient in the present case and her two sisters, ADAMTS13 enzyme activity and antibody testing were not performed immediately due to a lack of congenital TTP diagnosis confirmation. Thus, appropriate treatments, such as fresh frozen plasma transfusion were not provided, and the patients eventually died. Their diagnoses of congenital TTP were only confirmed via postmortem genetic testing. The results from our analysis of these cases suggest that a significant reduction in ADAMTS13 enzyme activity is a key indicator of a congenital TTP diagnosis (15), such that a lower enzyme activity may correspond to an earlier onset in neonates $(16,17)$. Genetic testing can be used as an adjunct diagnostic tool. In addition, considering that the mother of the neonate in the present case had previously given birth to two live-born baby girls, both of whom died of jaundice and hemorrhage within $24 \mathrm{~h}$ of birth, the present case had a clear family history. 
Of the 12 neonates with congenital TTP reported in literature, three had a similar family history. Therefore, neonates exhibiting thrombocytopenia, severe hemorrhagic tendency, and jaundice of unknown etiology should raise suspicion of congenital TTP. In addition, early diagnosis and treatment should be performed to avoid adverse consequences. In inflammation, ADAMTS13 activity can also be reduced, but no more than $10 \%$. Under certain circumstances, severe ADAMTS13 enzyme deficiency could be masked by transfusions of any plasma-containing blood products (including plasma, red blood cell, or platelet transfusions). The testing of ADAMTS13 after plasma transfusion does not have any sense. Therefore, genetic testing may facilitate the diagnosis of congenital TTP (17). Furthermore, the PLASMIC score can be used as a rapid assessment tool for TTP (18). The PLASMIC scores assigned to the second and third births of the mother of the patient in the current case were 5 and 7 , respectively.

In the present case, comprehensive genetic screening of genes related to thrombocytopenic diseases via highthroughput sequencing showed that ADAMTS13 had a compound heterozygous mutation of c.1187 (exon10) $\mathrm{G}>\mathrm{A}$ (p.C396Y)/c.1595G > T (p.C532F). Pedigree verification of these variants confirmed an autosomal recessive inheritance pattern. According to the ACMG guidelines, these two mutations are classified as variants of uncertain significance (VUS), indicating that they have not been reported in genomic databases or in literature. Taken together, the clinical features, PLASMIC score, family history, and the presence of ADAMTS13 variants, strongly suggest congenital TTP in the present case. Additionally, the gene variant identified is a novel ADAMTS13 variant.

The treatment for Upshaw-Schulman syndrome (USS) is relatively simple, which is the supplementation of the deficient ADAMTS13 enzyme. Currently, since no purified ADAMTS13 enzyme preparation exists, ADAMTS13 enzyme in patients may be supplemented with fresh frozen plasma. Intermediate-purity factor VIII concentrate or recombinant ADAMTS13 concentrate is potentially safer and more effective treatments (19). The use of recombinant ADAMTS13 concentrate is currently under investigations in clinical trials. The half-life of ADAMTS13 enzyme is 2-3 days, suggesting that the clinical effect of plasma or factor VIII concentrate transfusion can be maintained for 10-20 days. All neonatal patients who were transfused with fresh frozen plasma after a diagnosis had been confirmed, irrespective of ondemand or prophylactic treatments, achieved a favorable state of remission. Of the 12 cases reported in the literature, only 3 died. The remaining nine cases were treated with timely plasma exchange following a confirmed diagnosis. All patients displayed

\section{REFERENCES}

1. Loirat C, Girma JP, Desconclois C, Coppo P, Veyradier A. Thrombotic thrombocytopenic purpura related to severe ADAMTS13 deficiency in children. Pediatr Nephrol. (2009) 24:19-29. doi: 10.1007/s00467-008-0863-5

2. Terrell DR, Williams LA, Vesely SK, Lämmle B, Hovinga JA, George JN. The incidence of thrombotic thrombocytopenic purpura-hemolytic uremic syndrome: all patients, idiopathic patients, and patients good prognosis following fresh frozen plasma transfusion. Longterm follow-ups also showed that all neonatal patients who received regular fresh frozen plasma transfusions achieved longterm remission. Prophylactic treatment is recommended for those with severe episodes combined with ischemic injury to organs or those with chronic forms of the disease. Transfusion should be given once every 2-4 weeks to maintain a safe platelet level and prevent clinical onset of disease. However, there is no consensus whether plasma therapy should be intensified to cover the most frequent triggering factors of TTP bouts in childhood, such as infections and vaccinations (20). In conclusion, congenital TTP is an inherited autosomal recessive disorder that is often mistaken for other conditions with immune-related cytopenias, such as ITP. Although the incidence is extremely low, neonatal patients who do not receive timely and accurate diagnosis and treatment will suffer severe adverse outcomes. In addition, accurate identification of congenital TTP relies on family history for initial diagnosis, ADAMTS13 enzyme activity testing to confirm diagnosis, and genetic testing to facilitate diagnosis. The initiation of effective replacement therapy following a confirmed diagnosis can prevent relapse and improve the quality of life of neonatal patients with TTP.

\section{DATA AVAILABILITY STATEMENT}

All datasets generated for this study are included in the article/supplementary material.

\section{ETHICS STATEMENT}

Written informed consent was obtained from the individual(s), and minor(s)' legal guardian/next of kin, for the publication of any potentially identifiable images or data included in this article.

\section{AUTHOR CONTRIBUTIONS}

JW conceptualized and designed the case report and reviewed and revised the manuscript. LZ developed initial draft, reviewed and revised the manuscript, and approved the final manuscript as submitted. All authors contributed to the article and approved the submitted version.

\section{ACKNOWLEDGMENTS}

We would like to thank Editage (www.editage.cn) for english language editing. 
acquired thrombotic thrombocytopenic purpura. Arch Pathol Lab Med. (2014) 138:546-9. doi: 10.5858/arpa.2013-0170-OA

5. Sharma D, Shastri S, Pandita A, Sharma P. Congenital thrombotic thrombocytopenic purpura: Upshaw-Schulman syndrome: a cause of neonatal death and review of literature. J Matern Fetal Neonatal Med. (2016) 29:1977-9. doi: 10.3109/14767058.2015.10 71789

6. Lehmberg K, Hassenpflug WA, Klaassen I, Hillebrand G, Oyen F, Budde U, et al. Inherited thrombotic thrombocytopenic purpura (Upshaw Schulman syndrome) as differential diagnosis to neonatal septicaemia with disseminated intravascular coagulation - a case series. Z Geburtshilfe Neonatol. (2017) 221:39-42. doi: 10.1055/s-0042-109404

7. Tsujii N, Shiraishi I, Kokame K, Shima M, Fujimura Y, Takahashi Y, et al. Severe hemolysis and pulmonary hypertension in a neonate with Upshaw-Schulman syndrome. Pediatrics. (2016):138:e20161565. doi: 10.1542/peds.2016-4105

8. Tanabe S, Yagi H, Kimura $\mathrm{T}$, Isonishi A, Kato S, Yoshida $\mathrm{Y}$, et al. Two newborn-onset patients of Upshaw-Schulman syndrome with distinct subsequent clinical courses. Int J Hematol. (2012) 96:78997. doi: 10.1007/s12185-012-1221-8

9. Ghariani I, Jmili-Braham N, Azzebi O, Kortas M, Veyradier A, Bakir L. Purpura thrombotique thrombocytopénique chez un nouveau-né [Thrombotic thrombocytopenic purpura in a newborn]. Arch Pediatr. (2016) 23:78-81. doi: 10.1016/j.arcped.2015.09.032

10. Sudour H, Rouabah M, Mansuy L, Bordigoni P, Hascoet JM. Purpura thrombotique thrombocytopénique chez un nouveau-né [Thrombotic thrombocytopenic purpura in a newborn]. Arch Pediatr. (2007) 14:3942. doi: 10.1016/j.arcped.2006.10.016

11. Jubinsky PT, Moraille R, Tsai HM. Thrombotic thrombocytopenic purpura in a newborn. J Perinatol. (2003) 23:85-7. doi: 10.1038/sj.jp. 7210853

12. Kentouche K, Budde U, Furlan M, Scharfe V, Schneppenheim R, Zintl F. Remission of thrombotic thrombocytopenic purpura in a patient with compound heterozygous deficiency of von Willebrand factor-cleaving protease by infusion of solvent/detergent plasma. Acta Paediatr. (2002) 91:1056-9. doi: 10.1111/j.1651-2227.2002.tb 00099.x
13. Hager HB, Andersen MT. A neonate presenting with jaundice, anemia, and thrombocytopenia. Blood. (2018) 131:1627. doi: 10.1182/blood-2018-01-827063

14. Guo W, Zhang HL, Li L. Thrombotic thrombocytopenic purpura in newborn, one case report. Chin J Child Health Care. (2016) 24:223-4. doi: 10.11852/zgetbjzz2016-24-02-34

15. Ferrari B, Cairo A, Pontiggia S, Mancini I, Masini L, Peyvandi F. Congenital and acquired ADAMTS13 deficiency: two mechanisms, one patient. J Clin Apher. (2015) 30:252-6. doi: 10.1002/jca.21366

16. Lotta LA, Wu HM, Mackie IJ, Noris M, Veyradier A, Scully MA, et al. Residual plasmatic activity of ADAMTS13 is correlated with phenotype severity in congenital thrombotic thrombocytopenic purpura. Blood. (2012) 120:4408. doi: 10.1182/blood-2012-01-403113

17. Hanby HA, Zheng XL. Current status in diagnosis and treatment of hereditary thrombotic thrombocytopenic purpura. Hereditary Genet. (2014) 3:e108. doi: 10.4172/2161-1041.1000e108

18. Bendapudi PK, Hurwitz S, Fry A, Marques MB, Waldo SW, Li A, et al. Derivation and external validation of the PLASMIC score for rapid assessment of adults with thrombotic microangiopathies: a cohort study. Lancet Haematol. (2017) 4:e157-64. doi: 10.1016/S2352-3026(17)30026-1

19. Aledort LM, Singleton TC, Ulsh PJ. Treatment of congenital thrombotic thrombocytopenia purpura: a new paradigm. J Pediatr Hematol Oncol. (2017) 39:524-7. doi: 10.1097/MPH.0000000000000917

20. Coppo P, Veyradier A. Current management and therapeutical perspectives in thrombotic thrombocytopenic purpura. Presse Med. (2012) 41(3 Pt 2):e16376. doi: 10.1016/j.lpm.2011.10.024

Conflict of Interest: The authors declare that the research was conducted in the absence of any commercial or financial relationships that could be construed as a potential conflict of interest.

Copyright (c) 2020 Wang and Zhao. This is an open-access article distributed under the terms of the Creative Commons Attribution License (CC BY). The use, distribution or reproduction in other forums is permitted, provided the original author(s) and the copyright owner(s) are credited and that the original publication in this journal is cited, in accordance with accepted academic practice. No use, distribution or reproduction is permitted which does not comply with these terms. 